\title{
Teacher-Student Reflections: A Critical Conversation about Values and Cultural Awareness in Community Development Work, and Implications for Teaching and Practice
}

\author{
Louise Sheridan *(i) and Matthew Mungai \\ School of Education, University of Glasgow, 11 Eldon Street, Glasgow G3 6NH, UK; Mattmungai5@gmail.com \\ * Correspondence: louise.sheridan@glasgow.ac.uk
}

check for

updates

Citation: Sheridan, L.; Mungai, M. Teacher-Student Reflections: A

Critical Conversation about Values and Cultural Awareness in

Community Development Work, and Implications for Teaching and Practice. Educ. Sci. 2021, 11, 526. https://doi.org/10.3390/

educsci11090526

Academic Editors: Pam Alldred and Frances Howard

Received: 5 June 2021

Accepted: 3 September 2021

Published: 9 September 2021

Publisher's Note: MDPI stays neutral with regard to jurisdictional claims in published maps and institutional affiliations.

Copyright: (C) 2021 by the authors. Licensee MDPI, Basel, Switzerland. This article is an open access article distributed under the terms and conditions of the Creative Commons Attribution (CC BY) license (https:/ / creativecommons.org/licenses/by/ $4.0 /)$.

\begin{abstract}
This reflective, autoethnographic piece provides some insights into our involvement with a program that promotes a value-driven approach to community development work. As a 'conversation' between a lecturer and a graduate, or Educator of Informal Educators and Informal Educator, we discuss the process of teaching and learning about values within day-to-day community development practice. We emphasise that a value-driven approach enables informal educators to celebrate cultural diversity, which can be complex in community settings. As the educator of informal educators (Louise), I reflect on the need to explore and demonstrate what value-driven practice looks like in day-to-day practice within community work and not simply state that values are important. This was prompted by self-reflection and the realisation that my teaching failed to illuminate how to bring values to life in all aspects of community work to achieve anti-discriminatory, inclusive and empowering practice. As an informal educator (Matthew), I consider how community development theories and values translate into meaningful practice that celebrates cultural diversity. Reflections are influenced by theories from Paulo Freire, with a focus on his notion that 'educators should respect the autonomy of the students and respect cultural identities'. An example of Freirean dialogue, the article discusses our critical consciousness through praxis as educator and informal educator. Acknowledging that we are never fully complete — we are always 'becoming' —we hope the article will be of interest to both Educators of Informal Educators and Informal Educators alike.
\end{abstract}

Keywords: community development; values; social justice; cultural diversity; informal educators

\section{Introduction}

As a 'conversation' between lecturer and graduate, this piece presents autoethnographic narratives on our involvement with an undergraduate program that promotes a value-driven approach to community development practice. The article captures our reflections as an Educator of Informal Educators and an Informal Educator. We emphasise that a value-driven approach enables informal educators to celebrate cultural diversity, influenced by Freire's principle that educators should respect people's autonomy and cultural experiences [1]. As the educator of informal educators (Louise), I reflect on the need to explore and demonstrate what value-driven practice [2] looks like in day-to-day practice within community work and not simply state that values are important. This was prompted by self-reflection and the realisation that my teaching failed to illuminate how to bring values to life in all aspects of community work. As an informal educator (Matthew), I consider how community development theories and values translate into meaningful practice that celebrates cultural diversity. For clarity, the terms informal educator, community worker and community development practitioner are used interchangeably. For this article, these terms refer to people who work, paid or unpaid, in diverse community contexts to support communities that strive for justice and equality. We hope to provide you, the reader, with some insights on how Paulo Freire's theories [3] are helpful in shaping positive educational experiences in both higher education settings and informal community settings. 


\section{A Statement of the Problem}

As a lecturer marking student assignments, it became apparent that many students were not able to fully articulate and demonstrate what value-driven community development practice involves on a day-to-day basis on placement. This prompted some reflection, followed by the realisation that the intricacies of bringing values to life had not been fully elaborated. Without a deeper understanding, informal educators could fail to apply values in a meaningful way. This has the potential to be disempowering, albeit unintentionally.

\section{The Context}

The Bachelor of Arts (Hons) Community Development (BACD) is part of the University of Glasgow, which is in Scotland - part of the United Kingdom (UK). The program is professionally endorsed by the Community Learning and Development Standards Council for Scotland and, as such, is an example of formal education that is certificated. It equips graduates to work as informal educators in the broad field of community work. The work they do can be associated with informal and non-formal learning. An example of informal learning might involve community members gaining knowledge by attending a community event. Non-formal education might involve a group learning more about a topic connected to a project in which they are involved, such as learning about housing rights. Through formal education, the BACD enables informal educators to gain skills, knowledge, and experience to work with communities and promotes learning as a lifelong activity [2] -a key value for community practitioners when working alongside communities. Informal and non-formal education is the bedrock of community development. The program promotes transformational learning [3] through community development methods and approaches to increase social, cultural, and political awareness and is underpinned by community development values. Table 1 presents a typology of values relating to community development practice, including values from The National Occupational Standards for Community Development [4] and the Community Learning and Development Standards Council for Scotland [2]. The typology combines two sets of values that form a thread throughout the curriculum of courses on the BACD program.

Influenced by values [2] and critical pedagogy [3], the role of the community worker is to support communities in their efforts to influence positive social change, examining structures, processes, and policies that are unfair. The process begins with the community worker actively listening to communities, hearing their stories, and co-creating a program of activities that culminate in collective action. In this process, community workers are informal educators, enabling creative and participatory learning experiences, as opposed to depositing knowledge to community members. Community workers are based in some of the most vulnerable communities within society; therefore, it is important that they are equipped with the knowledge and skills to ensure best practices.

The article is framed by a set of questions that we each answer: how we define community development; why values are so important in practice; how values enable culturally sensitive practice and promote anti-discrimination and inclusion; and finally, are Paulo Freire's theories still relevant to contemporary practice. We begin with a discussion about our interpretation of community development and the various approaches that are useful in enabling communities to work together for positive change. The article includes some honest reflections on my teaching practice as a lecturer, being mindful of the responsibility associated with educating informal educators who will work with vulnerable communities. It also considers how value-driven community development can celebrate cultural diversity and promote inclusive, anti-discriminatory practice [2]. Mindful that Paulo Freire's ideas feature throughout the program, the article questions if his ideas are still relevant in contemporary practice. An example of Freirean dialogue [3], the article reflects our critical consciousness as educator and informal educator, calling us to deeply reflect on our practice and make necessary changes in the name of social justice. 
Table 1. Typology of Community Development Values.

\begin{tabular}{|c|c|c|c|c|}
\hline \multicolumn{5}{|c|}{ Typology of Community Development Values } \\
\hline Autonomy & Equality and Justice & Action for Change & Collective Working & Learning through Life \\
\hline \multicolumn{5}{|c|}{ The Community Learning and Development Standards Council for Scotland Values } \\
\hline Self-Determination & Inclusion & Empowerment & $\begin{array}{c}\text { Working } \\
\text { Collaboratively }\end{array}$ & $\begin{array}{c}\text { Promotion of } \\
\text { Learning as a Lifelong } \\
\text { Activity } \\
\end{array}$ \\
\hline $\begin{array}{l}\text { Respecting the } \\
\text { individual and valuing } \\
\text { the right of people to } \\
\text { make their own choices }\end{array}$ & $\begin{array}{l}\text { Valuing equality of } \\
\text { both opportunity and } \\
\text { outcome, and } \\
\text { challenging } \\
\text { discriminatory practice }\end{array}$ & $\begin{array}{l}\text { Increasing the ability of } \\
\text { individuals and groups } \\
\text { to influence issues that } \\
\text { affect them and their } \\
\text { communities through } \\
\text { individual and/or } \\
\text { collective action }\end{array}$ & $\begin{array}{l}\text { Maximising } \\
\text { collaborative working } \\
\text { relationships in } \\
\text { partnerships between } \\
\text { the many agencies } \\
\text { which contribute to } \\
\text { CLD, including } \\
\text { collaborative work } \\
\text { with participants, } \\
\text { learners, and } \\
\text { communities }\end{array}$ & $\begin{array}{l}\text { Ensuring that } \\
\text { individuals are aware } \\
\text { of a range of learning } \\
\text { opportunities and can } \\
\text { access relevant options } \\
\text { at any stage of their life }\end{array}$ \\
\hline \multicolumn{5}{|c|}{ The National Occupational Standards for Community Development Values } \\
\hline & $\begin{array}{c}\text { Equality and } \\
\text { Anti-Discrimination }\end{array}$ & $\begin{array}{l}\text { Community } \\
\text { Empowerment }\end{array}$ & $\begin{array}{l}\text { Working and Learning } \\
\text { Together }\end{array}$ & \\
\hline & $\begin{array}{c}\text { Community } \\
\text { development } \\
\text { practitioners will work } \\
\text { with communities and } \\
\text { organisations to } \\
\text { challenge the } \\
\text { oppression and } \\
\text { exclusion of } \\
\text { individuals and groups }\end{array}$ & $\begin{array}{c}\text { Community } \\
\text { development } \\
\text { practitioners will work } \\
\text { with communities and } \\
\text { organisations to work } \\
\text { together }\end{array}$ & $\begin{array}{c}\text { Community } \\
\text { development } \\
\text { practitioners will } \\
\text { support individuals } \\
\text { and communities } \\
\text { working and learning } \\
\text { together }\end{array}$ & \\
\hline & Social Justice & Collective Action & & \\
\hline & $\begin{array}{c}\text { Community } \\
\text { development } \\
\text { practitioners will work } \\
\text { with communities and } \\
\text { organisations to } \\
\text { achieve change and the } \\
\text { long-term goal of a } \\
\text { more equal, } \\
\text { non-sectarian society }\end{array}$ & $\begin{array}{c}\text { Community } \\
\text { development } \\
\text { practitioners will work } \\
\text { with communities to } \\
\text { organise, influence and } \\
\text { take action }\end{array}$ & & \\
\hline
\end{tabular}

\section{Community Development-A Student and a Teacher's View}

There Are Many Interpretations of Community Development, How Would You Define It?

Matthew: As a student in the University of Glasgow's BACD program, I came across various definitions and approaches of community development. For example, Kretzmann and McKnight's [5] Asset Based Community Development focuses on utilising the resources and assets of a community to formulate strategies for addressing social challenges. This approach, as I came to learn, draws insights from Cooperrider et al.'s [6] Appreciative Inquiry (AI) business model, which entails collective inquiry to highlight the strengths of an organisation, followed by the cohesive design of the desired outcome. This leads to collective action for the realisation of that outcome through which the strengths of the organisation are accentuated. Other approaches are more radical, such as Alinsky's [7] community organising, which involves working with communities to help them strategically apply pressure to decision-makers, including politicians, business owners, and 
property owners, to bring about change. This method is applied by community activists all over the world and has been used by human rights activists, including Obama, during his tenure as a community organiser [8]. Commonalities between the different approaches to Community Development became apparent to me, which enabled me to develop my own understanding. It is important to note that my perspectives are influenced by my lived experiences as someone who faced social injustices due to my background as a black African man in Glasgow. Therefore, the narrative I give in this conversation with you, Louise, is unique to myself and cannot be used as a basis to generalise experiences in the entire BACD programme because experiences may vary from person to person.

I came to understand that values, such as participation and anti-discrimination, are the common thread that underpin the different approaches. Community Development is a process that brings about positive social change, through which people increase their critical consciousness [3]. The Community Development Jigsaw (Figure 1) [9] was the framework for students' practice, which helped to guide the work that I did within communities.

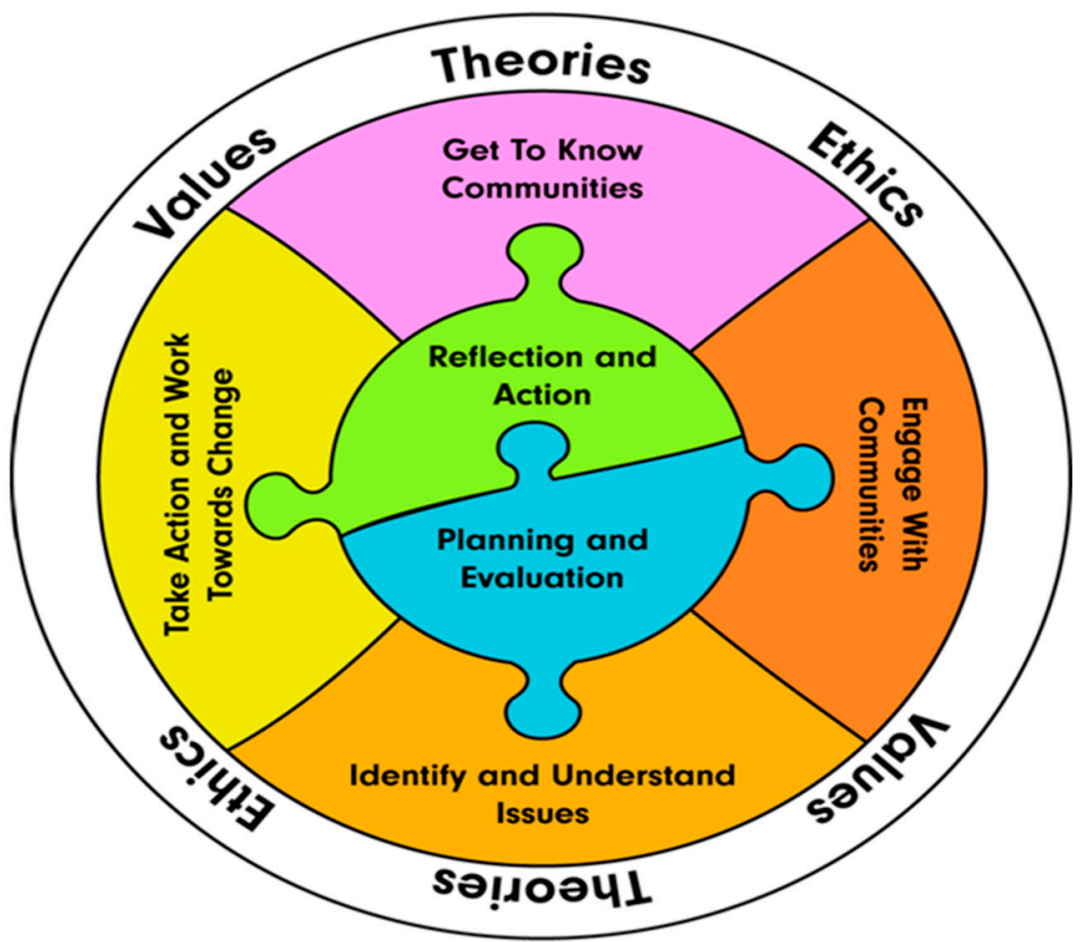

Figure 1. The Community Development Jigsaw.

My first-year placement was at an Integration Network, where I worked with Ethnic Minority community groups to coordinate activities that would facilitate integration within their local communities. We adopted a community-centred approach to integration, which entailed both host and new community members coming together to create spaces in which both groups could thrive. For this to work, both host and new community members must compromise on certain aspects of their cultures and values to enable integration. This placement resonated with me due to my background as an immigrant. Many participants who attended the activities I facilitated were asylum seekers and refugees. I empathised with them, having been through a racist and discriminatory immigration system myself. I shared my experiences of integrating in the UK with participants in the men's group through activities including focus group discussions and informal one-to-one exchanges. As the informal educator, I had to create a safe space where the participants felt that they could share their experiences without being judged and discriminated against. Firstly, I gave a brief but honest account of the challenges that I faced through my life and how I dealt with these situations. Sharing my experiences as a young boy in school was informative to parents with children attending school in the UK. For instance, they were not aware of 
the social pressures that their children may encounter in education as they had no prior experience of the UK educational system. Sharing the challenges I faced as an adult was particularly useful for those who had recently arrived in the UK and had not established strong networks. I found this would often prompt discussions on the different challenges we faced as migrants, regardless of our status in the UK. What stood out to me was that migrant groups faced different challenges on integration depending on their ethnicity or religious/cultural background. This is corroborated in research, as literature highlights that, indeed, a migrant's faith, racial ethnicity and nationality play a significant role in their integration experience in the UK. This is particularly evident in the media, where different migrant groups are either misrepresented and/or underrepresented, which adds to negative experiences of discrimination amongst migrant communities [10].

Initially, this experience was daunting to me. The participants in the focus group discussions were asylum seekers and refugees, and I was not. Therefore our interaction with the UK immigration system was different, and, as a result of this, so too was our experience integrating in the UK. Through working in Integration Networks, I learned that asylum seekers often face a strenuous ordeal, with the most vulnerable migrants facing dire circumstances such as destitution and the inability to work. These experiences are perpetuated by an inherently discriminatory system. I was able to apply the theory I learned as a student to my practice, ensuring that I brought values to life in my day-to-day work. It was experiences such as these that helped to deepen my understanding of community development. Through exchanging knowledge gained through lived experiences with other immigrants, we were able to create a network that provided a range of support, information, and advice. This included legal advice pertaining to immigration, as well as more informal information such as employment opportunities that had an empowering effect on new community members. Through collective action, a value and key element of community development [2], we came together to prohibit home office efforts in detaining vulnerable asylum seekers, including families at the immigration removal centre in Scotland. Witnessing and being part of events such as these confirmed the transformation that is possible through community development.

Louise: Through collective action, the Integration Network influenced a form of social change by preventing the detainment of vulnerable asylum seekers. At times, students doubt that theory translates into practice, but your experience demonstrates that change is possible through a thoughtful approach to community development. For me, supporting communities to bring about positive change is at the heart of community development, regardless of the method being used. As you note, the program teaches multiple approaches to community development, but you recognise that values are a core element. You mentioned the exchange of knowledge between community members and with you as an informal educator. This connects with another core element of community development- that communities must be at the heart of the process and should drive the agenda. Your efforts to enable people to share their experiences and cultures connect to Freire's [1] principle that educators should understand and value cultural diversity, as well as recognise people's ability as agents of change. It is important to recognise that community development is interpreted and applied in diverse ways and that ideology shapes the way that community development is constructed. Historically, community development was identified as a process that involved whole communities in ensuring economic and social progress. Implicit, though, is the belief that communities identified for such projects lack the ability to bring about positive change without help from external agents [8]. It is impossible to deny that many communities in Scotland and across the globe have been affected by multiple factors that have left them struggling in day-to-day existence. There is no question that communities affected by multiple levels of deprivation benefit from support. However, rather than advocating an approach to community development that does work to communities or does work for communities, the BACD emphasises the importance of working with communities. You exemplify this Matthew, by discussing the collective action you undertook with asylum seekers to prevent the detention of vulnerable 
asylum seekers. Success is further enabled by building and maintaining networks, which is what Gilchrist describes as a well-connected community [11].

The need to challenge injustice and inequality is a vital aspect of any conception of critical theory. However, focusing only on the problems within a community may have more of a debilitating effect. A deficit approach to working with communities involves only asking questions such as 'what would you change about your community?' or 'what are the problems in your community?', whereas an asset-based approach begins by asking 'what makes you proud about your community?'. Therefore, a balanced approach is necessary, combining elements from Freire's problem-posing approach in which generative themes reflect difficult lived realities, with aspects from appreciative inquiry that envisages a better future [1]. Regardless of the method of engagement, it is vital for practitioners to convey that they believe communities have power and the ability to act with others to effect positive change. On reflection, this was something I took for granted, that students would inherently know they should embody this positive belief in their day-to-day actions. Through my doctoral study, I came to realise that, as teachers, we should not assume that students instinctively know how to be when they apply these methods and approaches. This led me to develop the concept of 'alfirmo' [12], which means conveying the belief in people's ability to achieve positive change, demonstrating care and compassion for people, and providing the necessary support when needed to help them achieve their goals. To return to the question about the definition of community development, it is a way of being with communities that embodies optimism, encourages solidarity and passion for social change. It is a lengthy process that combines the joys and challenges of working with groups of people and will be more meaningful and authentic when guided by ethics and values.

\section{Community Values and Day-to-Day Practice}

\section{Why Is It So Important to Take a Value-Driven Approach to Community Development?}

Louise: As discussed, there are multiple theories, approaches, and methods under the banner of community development. However, working 'with' communities is at the core [13]. Whatever the approach, whether it is community organising [7], appreciative inquiry [6], or any other, bringing values to life is imperative [14]. I have always been fully committed to teaching students about values, listing them with ease. Table 1 presents a typology that combines values from the National Occupational Standards for Community Development [4] and the Community Learning and Development Standards Council for Scotland [3]. Students were asked to write about how they brought these values to life in their practice. They were in no doubt that values were important in their work with communities; this message was explicit in my teaching. When some students reproduced these lists in essays, without fully exploring what value-driven practice looks like on a day-to-day basis, I began to question if I had been doing the right thing.

You refer to the Community Development Jigsaw [9] as a framework for students' practice, Matthew. Colleagues and I developed this (Figure 1) as a guide to the essential elements involved in working with communities. Each part of the jigsaw contributes to an overall approach to working with communities to achieve their goals and effect positive change. Again, students were in no doubt about the importance of values, underpinning all aspects of work, along with ethics and relevant theories. However, it is one thing to tell students, 'You must apply community development values in practice', and an altogether different thing to teach them 'how' to take a value-driven approach. I realised a deeper exploration of what value-driven practice involves was missing. I assumed that people would instinctively know that actions, decisions, and language used within the context of working with communities should be guided by values. One should never make assumptions, especially as a lecturer. I began to change my teaching practice.

I began to explore how to bring values to life in day-to-day practice. For example, for the value of inclusion [2], I encouraged the development of a group agreement. Many youth workers know that setting ground rules when working with groups of young people 
is an important part of the process. It is less common to do this when working with groups of adults. My recent experience of chairing meetings with representatives from multiple community groups, sometimes fraught with tensions, reinforced that a form of agreement is important in any context. It may feel obvious for some, but I realised the importance of exploring this in detail, teaching students that setting an agreement forms part of the process of creating a safe and inclusive space. This connects to Freire's principle for transformational practice that emphasises care and attention to create a conducive space for learning [1]. Discussions with students about them actively enforcing the agreement demonstrate how to bring the value to life. In setting the agreement, I encourage students to be honest with group members, explaining that they will intervene if someone is excluded from the conversation, albeit unintentionally. Simple actions, such as creating a safe atmosphere that enables people to build good relationships and to work together, is a way of ensuring a positive space that promotes trust and solidarity [12]. I am passionate about ensuring that students not only understand the importance of value-driven practice, which is an ethical imperative within community development, but also that they know how to ensure their practice is shaped by values. That is my hope, but I am not sure this was always the case. What was your experience of learning about values as a student?

Matthew: My experience was significantly influenced by my upbringing in a religious home. Integrity, which is defined here as adherence to strong moral principles and values both in private and public settings, was a trait consistently taught to me at home. When I joined the BACD program, I was taught to embody community development values-not just in my practice but also in my day-to-day life. This was a particularly challenging process for me because it clashed with my family's values. I began critiquing some of the beliefs with which I was brought up. I had to challenge traditional religious beliefs that were outdated or tailored to accommodate the hegemon. Often, this entailed debates with my parents and siblings on issues that contradicted the religious beliefs that we were accustomed to. However, as I believed in what they stood for, upholding them was necessary to become a successful community development practitioner.

To be effective in my practice, I had to adopt a critical perspective and demand more from myself. It is important for me to embody community development values in all aspects of my life. In my current role as a researcher, I am guided by the value of working and learning together, for example [2]. When monitoring and evaluating development interventions that have been conducted within communities, I ensure that I adopt a participatory approach. This entails working closely with communities who are the recipients of the interventions to gain insight into their lived experiences. The findings comprise communities' perspectives and feature in the final research reports. This practice challenges conventional methods of monitoring, evaluating, and implementing development projects, as it makes the community the primary stakeholder as opposed to the donors. Although funding is crucial for implementing projects, we must challenge topdown approaches to community development as they do little in addressing community issues [13]. As you previously mentioned, as community development practitioners, we cannot assume we know what ought to be done in communities. A key message I learned through the BACD program is that practitioners should support and enable communities to set the agenda and identify projects that will serve their needs.

I moved back to Kenya in 2019 after working with communities in Scotland for five years. I had to adapt my approach to community development, whilst still maintaining the values, to successfully work with communities in this context. This was a challenging process because not all communities align with Community Development values outlined by professional bodies in the United Kingdom [2]. This is partly due to cultural and religious beliefs that shape some community development interventions in Kenya. Understanding the differences has shaped my experience as a community development practitioner. I have found that standing firm in my values, particularly when they are challenged, gives me the opportunity to delve deeper into the concept of community development. The BACD program allowed me to do this with its unique structure, where $60 \%$ of the program is theory 
and $40 \%$ of the program involved the opportunity to go into communities and put theory to practice. This significantly enhanced my understanding of Community Development values, and indeed, reaffirmed their importance in Community Development practice.

\section{Cultural Diversity and Community Development \\ We Live in a Culturally Diverse World, What Helps Community Development Workers to Celebrate This?}

Matthew: Applying the Community Development values helps community development workers celebrate culture and diversity in the world. This is because the values encourage equal participation in communities, which harnesses perspectives and ideas gained through diverse cultural experiences. This is the essence of community development, as it encourages more dynamic communities in which everyone can contribute to shaping places that accommodate all cultures. Furthermore, community participation gives a sense of community ownership, which enhances sustainability. As community development workers and informal educators, it is our goal to become redundant in these communities as we facilitate the empowerment of the communities and eventually hand over the reins where the community can become self-sustaining. I learned that it is important for community development workers to apply the value of anti-discrimination to allow for the full participation of communities. Discriminating against groups prohibits equal participation, which results in a community where the needs of specific groups are neglected. Discrimination can be manifested in various forms, including direct discrimination, indirect discrimination, and intersectional discrimination [15]. Learning about the various forms is invaluable for any practitioner or informal educator.

Direct discrimination is defined as the unfair treatment of a group or individual because of a protected characteristic such as sex or race [15]. An example would include people from specific nationalities being prohibited from seeking asylum, applying for leave to remain, or accessing humanitarian aid to deter these specific nationalities from seeking asylum. During my work as a researcher, I witnessed people from red-listed countries in a state of limbo, where they cannot go back to their country of origin, as they are fleeing from both man-made and natural disasters. Indirect discrimination occurs when a law, practice, or policy is represented in a way where there are no defined distinctions made. It is presented neutrally, but it disproportionally disadvantages specific groups [16]. For example, the United Kingdom's asylum law states that to vote, one must produce a legal identification document. This includes a passport or driving license, which is only granted to those with legal status in the United Kingdom. This disregards groups, such as refugees, who reside and participate within communities. For some, the asylum process can take up to 15 years or more, which is a long time to be denied the right to participate in a crucial decision-making process that affects them directly. Intersectional discrimination occurs when multiple forms of discrimination occur at once, which leaves some groups even more disadvantaged. For example, discrimination against people with disabilities often means that they do not have the same opportunities as others, including employment and education. When people from a minority group also have a disability, there is a chance they will face greater barriers and exclusion, which is intersectional discrimination based on their ethnicity and disability [17].

To celebrate culture and diversity, it is imperative that discrimination is challenged in practice. For this to happen, we as community development workers and informal educators must first begin identifying privileges afforded to us and how they influence our interactions in the world. For example, as an able-bodied, heterosexual, educated black man, it became apparent to me, through my practice, how communities would react to me as I had certain privileges afforded to me by my education, gender, sexuality, and lack of disability. At the same time, I also became aware of certain negative stereotypes attached to my ethnicity. We live in an inherently biased world, where the narrative is shaped by a select few and by challenging that narrative, we can truly celebrate each other's differences and appreciate contributions from diverse cultures. That, for me, constitutes value-driven practice. 
Louise: As you note, change is only possible by challenging narratives that privilege some over others. Community development workers, youth workers, and informal educators can play a vital role, but the strength lies with people in communities. Two pieces of the community development jigsaw [9] are relevant here. A significant part of any community worker's job must be spent getting to know and engaging with the community. This must go beyond simply mapping the organisations, services, and resources that can be found within a community; this must involve building meaningful relationships with community members. Only then will community workers have a sense of the cultural diversity that exists within communities. Students on the BACD undertake forms of community mapping as part of course assessments and have produced some excellent results over the years. However, the focus is not always given to cultural diversity within communities. On reflection, I assumed that students would know that community mapping should involve insights into the diverse groups of people living in communities or participating within communities of function or interest. I now understand the need for me as an educator to be explicit about this. Gervedink [18] refers to the notion of culturally sensitive curriculum. I understand the need to ensure the curriculum I design reflects cultural diversity in ideas and literature, as well as promote the need for informal educators to do the same in their community contexts.

I must equip students as future informal educators with the knowledge and skills to understand the complexities of working with diverse groups and encourage them to celebrate and embrace cultural diversity. There are many ways that I can do this, and one includes enabling students to share their experiences of what has worked and what has not worked. The BACD regularly invites graduates to do Guest Lectures on the program, and some have been involved in Integration Projects as you were, Matthew. The Guest Lecture that you did on prejudice and white privilege was as enlightening for me as it was for the students. The notion of white privilege had gone unmentioned before then. It is important to create space to enable students, practitioners, and members of minority groups to share their insights and experiences. This should be a core part of the curriculum and not happen by chance. This should then translate into day-to-day practice when students graduate and become community workers and informal educators. Creating space to enable meaningful conversations for people to share and learn about experiences about being part of minority groups should be a core part of the job for all community workers and informal educators.

In recent times, I recognised that important topics had somehow drifted from the curriculum. The commitment to ensuring that students are aware of the importance of antidiscrimination and anti-oppression within their practice always remained. Nevertheless, the message was implicit at times. It is vital for us as educators of informal educators to be explicit in our teaching and to deal with complex and sometimes challenging themes. This includes ensuring that students understand the nature and impact of unconscious bias. This is underpinned by the need for students and community workers to be reflexive, examining their beliefs and judgments and how these translate in their day-to-day practice. This should be a core part of the curriculum and not depend on who is teaching a course. Similarly, enabling students to reflect on the ways in which white privilege permeates many aspects of life and institutions is crucial, as you suggest Matthew. This is an essential topic, particularly for students who are situated in contexts in which the population is predominantly white. Understanding intersectionality, as you mentioned, is also vital [17]. If, as educators, we do not discuss these factors that impact people's lives overtly, then our students may be reluctant to approach these subjects as they move into the field of community work. It should not only be those working in integration projects or projects working with asylum seekers and refugees who consider cultural diversity as a core part of their job. As you rightly note, we exist in a society in which injustice, inequality, and prejudice exist-as educators and community workers, we must use approaches that enable us to uncover these situations and strive for positive change. Paulo Freire's [3] approach to education involves consciousness-raising and dialogue, which necessitates critical analysis 
of unequal societal structures. His ideas weave through many courses across the program, but some might ask if his ideas are relevant beyond Brazil.

\section{Critical Pedagogy and Community Development}

How Relevant Are Freire's Ideas in Contemporary Practice?

Louise: As mentioned in the introduction, I am heavily influenced by Freire's work, with his theories and principles as a lens through which I investigated youth participation practice in my doctoral study [12]. It is therefore easy for me to argue that Freire's ideas remain relevant in a contemporary context; I acknowledge my biased position. However, through my involvement with Youth and Community Programs in Higher Education Institutions in Scotland and England, I know Freire remains firm within the curriculum. In Macrine's view, 'the threatening triangulation of neoliberalism, conservatism, and nationalism has significantly intensified austerity politics, weakened gender equality, hollowed public education, created economic alienation, and harshened immigration policies' [19]; the picture is bleak. Across the globe, contemporary society faces many of the challenges experienced decades ago. In the 1960s, Freire initially developed his transformational educational approach in Brazil at a time when the masses experienced poverty and oppression. His approach aimed to support people to transform society, a process that enables the 'oppressed [to] exert their collective power to challenge injustice and ensure that people are treated fairly' [3].

Brazil remains fragile, much like many countries, with an economy that encapsulates a significant lack of employment opportunities and enduring poverty and inequality [19]. Despite this, the current Brazilian government has attempted to erase all traces of Freirean theories and approaches, with teachers prohibited to teach his ideas for fear of repercussions [19]. With the pervasive nature of dominant ideologies described by Macrine, Freire's critical pedagogy has never been needed more [3]. Giroux describes critical pedagogy as an educational approach that enables learners to engage in dialogue that begins with their lived experiences and incorporates critical analysis as routine, examining all aspects of society for systems of power that exclude [20]. It is based on hope and a vision for social justice for all.

The community development approach endorsed within the University of Glasgow is deeply influenced by Freire and critical pedagogy. The theories, principles, approaches, and methods are woven throughout all courses on the program. As lecturers, we must be clear about our position, that our 'brand' of community development is one that aims to challenge the status quo. Freire's critical pedagogy provides an approach to disrupt that which seems inevitable, offering a way to reimagine the future [3]. Freire urged against a sense of fatalism, or the hegemonic forces of neo-liberalism, where inequality is inevitable and 'opportunities for change become invisible' [3]. Jackson asserted that Freire's ideas were utopian, that his language of hope was too idealistic [21]. It cannot be denied that a language of optimism permeates the body of Freire's work. This is part of the reason that Freire's ideas remain relevant today; hope is needed to counter the negative impacts of neoliberalism and capitalism. Without a doubt, Freire's theories, principles, and methods remain firm within the curriculum. His ideas remain part of the community development worker's armoury to enable them to work with communities for social justice and equity. Are Freire's ideas and popular education approach still useful to you as a graduate and practitioner?

Matthew: I believe Freire's ideology still permeates through community development practice today. What resonates most is the concept of conscientisation [3]. This is a constant process of reflection and action where an individual becomes aware of his/her own social reality and then taking it a step further to take action to become active agents in changing the reality. As a researcher, adopting a critical perspective is crucial as it is how new truths and ideologies are derived. This was constantly communicated to me as a student on the BACD program by lecturers; they insisted that, as aspiring researchers and community development practitioners, we cannot take things for granted. 
Contrary to traditional methods of education, we ought to encourage learners to think for themselves but also work cohesively together to overcome barriers to social justice. As you previously mentioned, Freire's concepts are often viewed as utopian. This is further exacerbated because the evidence on how to operationalise his ideas is relatively scarce. However, the BACD program provided space for students to experiment with approaches underpinned by Freire's ethos that are used today. In my second year in the program, I undertook a placement with a young people's community theatre group in Glasgow. It was here I was able to experiment with Augusto Boals' concept of using theatre as a platform for engaging communities in societal issues [22]. It was here that I saw concrete evidence of the various methodologies through which Freire's concepts can be operationalised in the most creative ways. The challenge in operationalising concepts like 'dialogue' is more on creating a safe space where communities can come together and begin becoming active agents in their own realities. One of the theories that elevated my work as a community development practitioner was Tuckman's theory of group development [23]. Tuckman initially identified four stages of development within the life of a group, which consisted of forming, storming, norming, and performing. He later added the final stage of development, which is that of adjourning [24]. It was useful to learn that groups go through each stage to reach peak performance. Understanding what to expect in each stage helped me incorporate Freirean concepts in my practice.

I believe that Freirean concepts can be replicated in any community, or educational setting, including formal education. It is imperative that learners engage in dialogue, sharing their lived experiences and understanding the structures of society. Dialogue must lead to action. Without action, conversations are simply verbalism [3]. Informal educators, or teachers, play a significant role in creating a conducive space where both educators and students participate in a learning journey together. Learners are not empty vessels to be 'filled' with knowledge to conform to societal expectations. Learners should be active in the process, with informal educators naming the world and shaping the world. Aronowitz reaffirms this in his dissection of Freire's Pedagogy of the oppressed. He highlights three key goals for learners to achieve to attain critical awakening. The first is critical reflection to develop an understanding of the world, including its psychological, economic and political spheres. The second goal is to become aware of the forces that control our reality by understanding that we are all products of a flawed society controlled by a hegemon. The third is to create an environment that produces new knowledge and structures, where power is shared between those who create the social world through transforming themselves and nature [25]. Freire's process of de codification provides a vehicle through which to achieve these goals. I agree that his ideas are still as relevant now as they ever were.

\section{Conclusions}

With some honest reflections, this article confirms Freire's assertion that we are all unfinished beings [3]. As an educator of informal educators and an informal educator, we discuss our responsibility to critically engage with the world and to critically reflect on our own practice to ensure we do not drift from our commitments to values. It affirms our obligation to challenge discrimination of all forms and to encourage anti-discrimination in those with whom we work. We recognise that we refer to a higher education program situated in the United Kingdom, underpinned by a typology of values that may seem particular to that context. However, the theories, approaches, and values are applicable in global contexts. This has been demonstrated by international students who have taken BACD courses as electives. This article is not an attempt to promote the BACD, but rather, it is a call for educators in formal settings, such as higher education, to bring ideas to life. For instance, it is not enough to name community development values-to tell informal educators they must embody these values within their practice. Educators of informal educators must elucidate how to bring values to life in day-to-day practice. Understanding and celebrating cultural differences is crucial for all community workers 
and informal educators. The process of getting to know, and engaging with communities, is a core part of community work and should facilitate deep understanding of cultural differences and diversity [7]. This, in turn, should enable communities to co-exist and work together towards positive social change that will benefit all. Until injustice and inequality are eradicated, Freire's [3] transformational approach remains relevant in contemporary community work practice regardless of the context.

Funding: This research received no external funding.

Conflicts of Interest: The authors declare no conflict of interest.

\section{References}

1. Freire, P. Letters to Cristina Reflections on My Life and Work; Routledge: London, UK; New York, NY, USA, 1996.

2. Community Learning and Development Standards Council for Scotland. Available online: http://cldstandardscouncil.org.uk/ resources/values-of-cld/ValuesofCLD (accessed on 28 May 2020).

3. Freire, P. Pedagogy of the Oppressed, 30th ed.; Continuum: New York, NY, USA, 2000.

4. Lifelong Learning UK. National Occupational Standards for Community Development; Lifelong Learning UK: London, UK, 2009.

5. Kretzmann, J.; McKnight, J. Building Communities from the Inside Out: A Path Toward Finding and Mobilizing a Community's Assets, The Asset-Based Community; Institute for Policy Research: Evanston, IL, USA, 1993.

6. Cooperrider, D.L.; Whitney, D.; Stavros, J.M. The Appreciative Inquiry Handbook: For Leaders of Change, 2nd ed.; Berrett-Koehler: San Francisco, CA, USA, 2008.

7. Alinsky, S.D. Rules for Radicals: A Practical Primer for Realistic Radicals; Vintage Books: New York, NY, USA, 1971.

8. Hyatt, S.B. The Obama Victory, Asset-Based Development and the Re-Politicization of Community Organizing. N. Amer. Dialogue 2008, 11, 17-26. [CrossRef]

9. Sheridan, L.; Martin, H.; McDonald, A. Community Development Jigsaw. In Proceedings of the World Community Development Conference, Dundee, Scotland, 23-30 June 2019.

10. Eberl, J.-M.; Meltzer, C.E.; Heidenreich, T.; Herrero, B.; Theorin, N.; Lind, F.; Berganza, R.; Boomgaarden, H.G.; Schemer, C.; Strömbäck, J. The European media discourse on immigration and its effects: A literature review. Ann. Int. Commun. Assoc. 2018, 42, 207-223. [CrossRef]

11. Gilchrist, A. The Well-Connected Community. A Networking Approach to Community Development, 3rd ed.; Policy Press: Bristol, UK, 2019.

12. Sheridan, L. Youth Participation in North Ayrshire, Scotland, From a Freirean Perspective. Ph.D. Thesis, University of Glasgow, Glasgow, UK, 2018.

13. Somerville, P. Understanding Community; Policy Press: Bristol, UK, 2011.

14. Sheridan, L. Community Development-A Value-Driven Affair. Radic. Community Work. J. 2020, 4, 1-17. Available online: http:/ / www.rcwjournal.org/ojs/index.php/radcw/article/view/79 (accessed on 7 September 2021).

15. Federation for Community Development Learning. Available online: https://www.fcdl.org.uk/ (accessed on 23 April 2021).

16. Afrane, S.; Naku, D. Local Community Development and the Participatory Planning Approach: A Review of Theory and Practice. Curr. Res. Soc. Sci. 2013, 5, 185-191.

17. Crenshaw, K. Mapping the Margins: Intersectionality, Identity Politics, and Violence against Women of Color. Stanf. Law Rev. 1991, 43, 1241-1299. [CrossRef]

18. Gervedink, N.C. Culturally Sensitive Curriculum Development. In Collaborative Curriculum Design for Sustainable Innovation and Teacher Learning; Pieters, J., Voogt, J., Pareja Roblin, N., Eds.; Springer: Berlin/Heidelberg, Germany, 2019. [CrossRef]

19. Macrine, S.L. (Ed.) Introduction. In Critical Pedagogy in Uncertain Times Hope and Possibilities; Palgrave MacMillan: New York, NY, USA, 2009; pp. 1-8.

20. Giroux, H.A. The Attack on Higher Education and the Necessity of Critical Pedagogy. In Critical Pedagogy in Uncertain Times Hope and Possibilities; Macrine, S., Ed.; Palgrave MacMillan: New York, NY, USA, 2009; pp. 11-26.

21. Jackson, S. Freire Re-viewed. Educ. Theory 2007, 57, 199-213. [CrossRef]

22. Boal, A. Theatre of the Oppressed, 7th ed.; Theatre Communications Group: New York, NY, USA, 1985.

23. Tuckman, B.W. Developmental sequence in small groups. Psychol. Bull. 1965, 63, 384-399. [CrossRef] [PubMed]

24. Tuckman, B.W.; Jensen, M.A.C. Stages of Small-Group Development Revisited. Group Organ. Stud. 1977, 2, 419-427. [CrossRef]

25. Aronowitz, S. Paulo Freire's Radical Democratic Humanism: The Fetish of Method. Counterpoints 2012, 422, $257-274$. Available online: https:/ / www.jstor.org/stable/42981762 (accessed on 7 September 2021). 